\title{
Special care wards: are they special?
}

\author{
Anthony Zigmond
}

Over the past four years I have visited a number of special care wards (also known as locked/intensive care/secure wards) and interviewed many staff and patients, both as a Mental Health Act Commissioner and as a second opinion appointed doctor. It has been suggested to me that my observations may be of some interest. The points are not exhaustive nor are they research based. Before continuing I must also declare that I have no special knowledge or expertise in the care or treatment of patients in this setting.

\section{Background}

Every district health authority should, in line with existing government policy, ensure the availabilty of secure provision for patients with mental illness or learning disabilities. This should include provision for intensive care as well as for those who require long-term treatment and/or care (Department of Health \& Home Office, 1991).

In 1991, according to Regional Health Authorities returns, there were 639 beds for mental illness and 274 beds for learning disability in some form of local security (Department of Health \& Home Office, 1991).

\section{The patients}

The first point to recognise is self-evident. The patient population is very different from that on open wards. Almost all are detained under a section of the Mental Health Act. This does not make the population heterogeneous. Some of the patients are among the sickest in any district's service. They commonly have seriously disturbed behaviour. Others, particularly those sent on assessment from the courts or prison, may show little in the way of psychotic behaviour but may still be markedly self-destructive or violent. They may resent being placed with those they see as mad. Patients (and their families) on civil sections transferred from open wards have different expectations about their treatment from those on court orders or from special hospitals.

\section{The ward}

It is not only the patients who are different. There is rarely more than one special care ward in each district. There is no comparison ward. It is often physically apart from the admission wards and viewed as different from them by both staff and patients. Staff see it as different because of the different criteria for admission (all patients detained, admissions to be 'screened' by ward staff, numbers of staff etc.); patients because of the notion of a 'punishment ward'. It is the usual site for the seclusion room. The presence of a seclusion room, however little used, is commonly perceived as an ever present threat.

The fabric of the ward often takes a battering. Furniture may be damaged. This leads to a deterioration in the living and working environment which slowly becomes seen as acceptable for this group of patients. The ward may be devoid of 'homely' items such as pictures or flowers or other items which "may be used as weapons".

\section{The stafi}

Generally there is only one consultant. There is no local peer group. The relationship between the consultant and the senior nurse tends to be different from those wards which have several admitting consultants. The consultant may see him or herself as being permanently on call. This is viewed as dedication by the consultant, as supportive by the special care nursing staff and as suspicious by everyone else. It reinforces the view of a close (for this word read inappropriate), and excluding, relationship between medical and nursing staff. It is not 
unusual for there to be no, or very limited, input from disciplines other than medicine and nursing.

\section{The regime}

The next group of issues is brought about because all the patients are detained. All are locked up. There is no dilution with informal patients. Few patients can refuse medication. Even fewer believe they can. None can take their own discharge. Patients cannot go for a walk, take fresh air, watch television and so on, without permission. Many patients develop the belief, often but not always erroneously, that permission is required to go to bed early or to get up and read during the night. Permission for many activities (including fresh air or exercise) is often refused on the grounds of staff shortages. Patients cannot leave if they feel the standard of care is inadequate.

Routine on the ward is often overpowering. Patients do not visit off-ward areas. There are no unexpected visitors. All visits are planned. No outsiders are sitting on the ward. Not even managers can 'just pop on'. The locked door serves more than one purpose. It is common to see a notice on the door requesting that the bell be rung even by those with a key.

\section{The effects}

In my opinion these factors contribute to a number of features which can be seen on some special care wards.

(a) Staff feel isolated and unsupported. They feel outsiders do not understand the special circumstances in which they work. They may become increasingly dependent on each other to the point where they are unable to look critically at their own service. I have seen the development of what I can only describe as a siege mentality. Almost any challenge to accepted practice leads to questions about competence. This is particularly important in relation to the role of the 'on call' junior doctor. Ostensibly they are responsible for such decisions as prescribing emergency medication and use of seclusion. In practice they do as they are advised by nursing staff.

New staff, nursing, occupational therapy and so on, who question practice are told that they will learn. Failure to learn leads to exclusion.

(b) Caring only for very disturbed patients seems to make it much harder for staff to identify with the patients. Constant violence leads to brutalised staff. Together these factors seem to make it harder to maintain standards of humane care.

(c) This, in turn, leads to an increasing acceptance of a deteriorating ward environment. When I complained that patients were being made to sleep in a dormitory smeared with faeces it was pointed out to me that one of the patients had done this.

(d) There is acceptance of the restricted ward routine and lack of fresh air and exercise. There is no minimum standard such as exists for convicted criminals in prison. Restraint and seclusion may be seen as relatively minor further retrictions.

(e) High doses of medication become routine. At first new staff may comment on this. The 'needs' of this group of patients are explained to them. Visiting junior doctors with limited knowledge and experience rely on nursing staff who, they believe, are trained to offer advice about medication. Unsafe dosages are easily within reach.

\section{The solutions}

(a) Managers must visit the ward regularly, at least once each day. They should look around the ward not head straight for the nursing office. They should talk to patients as well as staff. Training should include visits to similar services in other districts.

(b) Heads of disciplines must meet regularly with senior ward staff and the consultant. This should not be for the purpose of inspection but for the sharing of ideas and problems between all those responsible for service provision. This should increase understanding, share responsibility and provide support for more junior members of staff. New, often junior, staff who question the regime, the environment or any other matter must 
feel they can seek advice and support from a senior member of their own discipline.

(c) There must be a budget which allows for regular repair and redecoration of the ward.

(d) Ward staff should rotate to open wards for six months every two years to avoid becoming cynical and to remind them how to accept 'No' from a patient. They should be seconded to and from other units if possible.

(e) The staff complement must be multidisciplinary.

(f) Junior medical staff should have specific training before they are 'on call' for such a unit.

(g) The patients' day should be described and include a minimum level of activity and fresh air.

(h) All episodes of restraint and seclusion should be fully documented. This should include a description of the incident, staff involved (including grades) and staff on duty at the time. The documents should be reviewed by management. A senior nurse should visit staff for debriefing following every episode of seclusion.

(i) If possible all patients should be interviewed on return to an open ward. There is no substitute for a consumer view.

Special care wards are an invaluable part of our services. Where they do not exist patients are more likely to be rejected, refused help or treated further from their home. A locked door can reduce the need for large doses of tranquillising medication and restraint. Patients on special care wards are usually the sickest in the service. Surely they deserve the highest standard of care.

\section{Reference}

DEPARTMENT OF HEALTH \& HOME OFFICE (1991) Review of Health and Social Services for Mentally Disordered Offenders and Others Requiring Similar Services.

Anthony Zigmond, Consultant Psychiatrist, Leeds Community \& Mental Health Services, High Royds Hospital, Menston, Ikley LS29 6AQ 